\title{
Retraction Notice to: Cauda Equina Syndrome: A Rare Presentation in Burkitt Lymphoma
}

\author{
Muhammad Idrees ${ }^{\text {a b }}$, Haisam Abid ${ }^{\text {a }}$, Timothy Korytko ${ }^{\text {a }}$
}

This retracts the Case Report article "Cauda Equina Syndrome: A Rare Presentation in Burkitt Lymphoma", by Idrees et al, published in Vol. 10, No. 6, 2019, p168-170, doi: http:// dx.doi.org/10.14740/jmc3308.

The authors would like to retract this article due to the existing conflicts of interest.

Manuscript submitted February 14, 2020, accepted February 17, 2020

aBassett Medical Center, Cooperstown, NY 13326, USA

${ }^{\mathrm{b} C}$ Corresponding Author: Muhammad Idrees, Bassett Medical Center, Coopers-

town, NY 13326, USA. Email: idreessoomro@gmail.com

doi: https://doi.org/10.14740/jmc3308r 